\title{
Thermal and morphological study of chitosan metal complexes
}

\author{
Fernanda Stuani Pereira ${ }^{1} \cdot$ Silvania Lanfredi $^{2} \cdot$ Eduardo René Pérez González $^{1}$. \\ Deuber Lincon da Silva Agostini ${ }^{3} \cdot$ Homero Marques Gomes $^{4} \cdot$ Ricardo dos Santos $^{2}$ \\ Medeiros ${ }^{1}$
}

Received: 20 September 2016/ Accepted: 4 February 2017/Published online: 16 February 2017

(C) Akadémiai Kiadó, Budapest, Hungary 2017

\begin{abstract}
The synthesis of chitosan Schiff bases, $N$-benzylidene chitosan (CTB), 4-dimethylamino-benzylidene chitosan (CTDB) and 4-nitro-benzylidene chitosan (CTNB), and their interaction with $\mathrm{Cu}^{2+}, \mathrm{Zn}^{2+}$ and $\mathrm{Ni}^{2+}$ were studied. The content of metal ions was determined by atomic absorption spectrometry, and the results showed that chitosan exhibited higher chelating capacity for the metal ions. Morphological changes of Schiff bases and complexes were demonstrated by SEM images. The presence of crystals attributed to copper sulfate adsorbed on the polymers surface was also observed, which indicates that part of the metal content is in the salt adsorbed and might influence in their further application studies. X-ray diffraction patterns showed that the formation of complexes resulted in the decrease in crystallinity. The thermal behavior of derivative and metal complexes were studied by
\end{abstract}

Electronic supplementary material The online version of this article (doi:10.1007/s10973-017-6146-2) contains supplementary material, which is available to authorized users.

Eduardo René Pérez González

eperez@fct.unesp.br

1 Laboratório de Química Orgânica Fina (LQOF),

Departamento de Química e Bioquimica, Campus de

Presidente Prudente, Univ Estadual Paulista,

C.P. 467, Presidente Prudente, SP 19060-900, Brazil

2 Laboratório de Compósitos e Cerâmicas Funcionais (LaCCeF), Departamento de Química e Bioquimica, Campus de Presidente Prudente, Univ Estadual Paulista, C.P. 467, Presidente Prudente, SP 19060-900, Brazil

3 Laboratório de Eletrofiação e Tecnologia, Departamento de Física, Campus de Presidente Prudente, Univ Estadual Paulista, C.P. 467, Presidente Prudente, SP 19060-900, Brazil

4 Departamento de Química e Bioquimica, Campus de Presidente Prudente, Univ Estadual Paulista, C.P. 467, Presidente Prudente, SP 19060-900, Brazil thermogravimetric analysis, differential thermogravimetric analysis and differential scanning calorimetry. The results showed that the presence of new groups and metal ions bonded to chitosan affected their thermal stability.

Keywords Chitosan $\cdot$ Schiff bases $\cdot$ Copper $\cdot$ Zinc . Nickel · Complexes

\section{Introduction}

The presence of amino and hydroxyl groups on chitosan structure provides the possibility of several chemical modifications in the polymer chain. These chemical modifications can be important because they enhance the polymer properties, such as selectivity, solubility, biological and chelating [1-3]. One important modification is related to Schiff bases, which are prepared from the condensation reaction of chitosan amino groups with an aldehyde or ketone. Schiff bases are characteristic for containing the $\mathrm{HC}=\mathrm{N}$ group.

The presence of imino groups in the polymer can increase the physiological activity of these materials [4], and moreover, electron-donating and electron-withdrawing substituents at the benzene ring, when the condensation reaction is carried out with aromatic aldehydes, can noticeably influence on the degree of substitution [5], thermal stability [6] and antibacterial activities. Seven Schiff bases were synthesized from $O$-carboxymethyl chitosan and para-substituted benzaldehydes. Antibacterial activities of the Schiff bases against Escherichia coli and Staphylococcus aureus were measured, and the tests showed that electron-donating group at the para position of benzaldehyde increases the antibacterial activities of chitosan Schiff bases, while electron-withdrawing group 
decreases the antibacterial activities [7]. Thermogravimetric studies of chitosan Schiff base polymers demonstrated that they are thermally stable and the variations in thermal stability are probably due to different degree of substitution. Moreover, the antimicrobial activities of derivatives were stronger than those of chitosan [8]. Chitosan-based materials have shown good adsorption capacities for wastewater treatment. In addition, the composites demonstrated better thermal stability mainly due to self-assembly and cross-linked nanostructures [9, 10]. Chitosan-crotonaldehyde Schiff base has been prepared and reported as good adsorbent for different metal ions and for different types of dyes. In addition, the material has also shown a strong antibacterial and antifungal activity and is an ecofriendly corrosion inhibitor for metal alloys [11].

More recently, novel chitosan Schiff bases were synthesized using 4-(2-chloroethyl)benzaldehyde and 4-(2-bromoethyl) benzaldehyde with a subsequent dehydrohalogenation to yield vinyl derivatives. These materials are interesting for polymerization and copolymerization reactions [12].

The chelation of chitosan Schiff bases with metal ions has gained attention because of their use as catalysts [13-15] and antibacterial agents [16]. 4-Hydroxysalicylidenechitosan Schiff base was prepared, and its complexation with several metal ions was investigated. The Schiff base behaves as a bidentate chelate with a single negative charge with the azomethine nitrogen and deprotonated 2-hydroxy centers [17]. A chitosan derivative was synthesized by the chemical modification of chitosan with vanillin-based complexing agent. The binding capacity of the derivative is in the order $\mathrm{Cu}(\mathrm{II})>$ $\mathrm{Ni}$ (II) $>\mathrm{Cd}$ (II) $\geq \mathrm{Co} \geq \mathrm{Mn}$ (II) $>\mathrm{Fe}$ (II) $>\mathrm{Pb}$ (II) in all studied pH ranges [18]. Jiao et al. [19] have reported the synthesis and characterization of three chitosan-based Schiff base compounds and the corresponding copper complexes. The results indicated that coordination reaction take place in Schiff base skeleton. The thermal stability of Schiff bases increased slightly, while that of the copper complexes was reduced significantly and the XRD results demonstrated a lower crystallinity of Schiff bases complexes. Chitosan-based Schiff base metal complexes were used as heterogeneous catalysts for the oxidation of $\beta$-isophorone with excellent activity [20]. Anthony et al. [21] have synthesized a Schiff base derived from chitosan and its $\mathrm{Cu}(\mathrm{II}), \mathrm{Co}$ (II) and $\mathrm{Ni}(\mathrm{II})$ complexes. X-ray diffraction patterns showed that the crystallinity of copper complex is found to be less than for nickel complex. Besides, the chemical modification of chitosan leads to increase the surface roughness, which makes them better catalysts.

Subsequent applications of chitosan-based Schiff bases metal complexes in biological and catalytic systems depend on the substituent of benzene ring and the amount of metal ions chelated by the derivatives [7, 22]. Thus, in the present study, we report the synthesis of three chitosan Schiff bases, $\mathrm{N}$-benzylidene chitosan (CTB), 4-dimethylamino- benzylidene chitosan (CTDB) and 4-nitro-benzylidene chitosan (CTNB), and their interaction with $\mathrm{Cu}(\mathrm{II}), \mathrm{Zn}(\mathrm{II})$ and $\mathrm{Ni}(\mathrm{II})$. The chemical structures of the Schiff bases and their metal complexes were investigated using the techniques ${ }^{13} \mathrm{C}$ CP-MAS NMR, AAS, SEM and XRD. Their thermal behavior was studied by TG and DSC.

\section{Materials and methods}

\section{Materials}

Chitosan from crab shells was purchased from SigmaAldrich, humidity: $11.8 \%$ and viscosity: $>400 \mathrm{mPa} \mathrm{s}, 1 \%$ in acetic acid, and was used without further purification. The deacetylation degree of chitosan was $78 \%$. The other chemical reagents used were of analytical grade. Benzaldehyde, 4-nitrobenzaldehyde, 4-(dimethylamino)benzaldehyde, copper(II) sulfate pentahydrate, zinc sulfate and nickel(II) chloride hexahydrate were purchased from Sigma-Aldrich and used without further purification.

\section{Synthesis of chitosan Schiff bases}

For the preparation of chitosan Schiff bases, $0.5 \mathrm{~g}$ of chitosan was dissolved in $15 \mathrm{~mL}$ of acetic acid $1 \%$ and the $\mathrm{pH}$ was adjusted to 4-5. The solution was diluted with $30 \mathrm{~mL}$ of ethanol and stirred at room temperature for $30 \mathrm{~min}$. After that, $2 \mathrm{mmol}$ of the corresponding aromatic aldehyde dissolved in $10 \mathrm{~mL}$ of ethanol (99\%) was added to the resulting viscous solution and the mixture was stirred for $8 \mathrm{~h}$. Then, the solvent was evaporated under reduced pressure and the product was washed with $15 \mathrm{~mL}$ of aqueous $\mathrm{NaHCO}_{3}(5 \%)$. The product was filtered off and washed with distilled water and ethanol to remove the excess of reagents. The resulting yellowish powders were dried for $4 \mathrm{~h}$ at $60{ }^{\circ} \mathrm{C}$.

\section{General procedure for preparation of chitosan and Schiff bases metal complexes}

The complexes were prepared by adding $0.1 \mathrm{~g}$ of dry chitosan or Schiff base (CTB, CTDB and CTNB) to $10 \mathrm{~mL}$ of $\mathrm{CuSO}_{4} \cdot 5 \mathrm{H}_{2} \mathrm{O}, \mathrm{ZnSO}_{4}$ or $\mathrm{NiCl}_{2} \cdot 6 \mathrm{H}_{2} \mathrm{O}$ aqueous solution $\left(0.01 \mathrm{~mol} \mathrm{~L}^{-1}\right)$ with stirring at room temperature for $24 \mathrm{~h}$. After that, the mixture was filtered off and the precipitate was dried in an oven at $60^{\circ} \mathrm{C}$ for $4 \mathrm{~h}$.

\section{Measurements}

Solid-state ${ }^{13} \mathrm{C}$ CP-MAS NMR spectra were recorded on an AVANCE III NMR spectrometer (Bruker, Campinas, Brazil, $400 \mathrm{MHz}$ ). The spin rate was kept at $10 \mathrm{kHz}$. 
$\mathrm{Cu}(\mathrm{II}), \mathrm{Zn}(\mathrm{II})$ and $\mathrm{Ni}(\mathrm{II})$ ions content of the remaining solution was measured by A Model Analyst 200 PerkinElmer Atomic Absorption Spectrometer in the optimal conditions recommended by the supplier for this quantification.

TG measurements were taken with a Netzsch TG 209. The powdered samples $(\sim 5 \mathrm{mg})$ were placed into alumina crucible and heated at $10{ }^{\circ} \mathrm{C} \mathrm{min}^{-1}$ under a dynamic nitrogen atmosphere at a flow rate of $25 \mathrm{~mL} \mathrm{~min}{ }^{-1}$ from room temperature to $700{ }^{\circ} \mathrm{C}$.

DSC measurements were taken in a Netzsch DSC Phoenix-204 using sample mass of $5 \mathrm{mg}$ in a covered aluminum crucible. An empty crucible was used as reference. The samples were heated at $10{ }^{\circ} \mathrm{C} \mathrm{min}^{-1}$ from room temperature to $500{ }^{\circ} \mathrm{C}$ with a gas flow rate of $25 \mathrm{~mL} \mathrm{~min}{ }^{-1}$.

The electron micrograph studies were carried out in Carls Zeiss EVO LS15 Model, with secondary electrons detector and high vacuum. Sputter Coater Quorum Model Q 150R ES was used to metalize the samples.

$\mathrm{X}$-ray diffractograms on powder samples were obtained using a SHIMADZU (model XRD-6000) diffractometer, with $\mathrm{Cu}-\mathrm{K}_{\alpha 1}$ radiation $(k=1.54056 \AA)$ and a graphite monochromator, at $40 \mathrm{kV}$ and a current of $30 \mathrm{~mA}$. Measurements were taken over an angular range of $5^{\circ} \leq 2 \theta \leq 40^{\circ}$ with a scanning step of 0.02 and a fixed counting time of $10 \mathrm{~s}$. Divergence, scattered and receiving radiation slits were $1^{\circ}, 1^{\circ}$ and $0.2 \mathrm{~mm}$, respectively.

\section{Results and discussion}

The Schiff bases have been synthesized by the condensation reaction of chitosan and different benzaldehydes. The representation of the Schiff bases preparation reaction is shown in Scheme 1.

\section{${ }^{13}$ c cp-mas nmr}

Figure 1 shows the ${ }^{13} \mathrm{C}$ NMR spectra of chitosan and its synthesized Schiff bases. The ${ }^{13} \mathrm{C}$ NMR spectrum of chitosan presents signals at $173.9 \mathrm{ppm}$ and at $23.7 \mathrm{ppm}$, which are attributed to the carbonyl carbon of $-\mathrm{COCH}_{3}$ and the methyl carbon $\left(-\mathrm{CH}_{3}\right)$, respectively, of acetylated unit. The signals between 56.6 and $104.4 \mathrm{ppm}$ are assigned to carbons $\mathrm{C} 1, \mathrm{C} 2, \mathrm{C} 2^{\prime}, \mathrm{C} 3, \mathrm{C} 4, \mathrm{C} 5$ and $\mathrm{C} 6$ of glypyranose [23]. The ${ }^{13} \mathrm{C}$ NMR spectra of chitosan Schiff bases show the signals of the carbons of pyranosidic ring between 56.6 and $104.4 \mathrm{ppm}$. Moreover, it can be observed the signals in the region of 164 and $167 \mathrm{ppm}$ assigned to $\mathrm{C} 9$ of the imine groups $(\mathrm{C}=\mathrm{N})$ [24] and the signals between 111 and $152 \mathrm{ppm}$ attributed to the carbons of the aromatic ring, which confirm the formation of the synthesized Schiff bases. It can also be seen a modification in the signal $\mathrm{C} 2$ at $\sim 56 \mathrm{ppm}$, because Schiff base reaction happens at this carbon, so there is a mixture of substituted and unsubstituted products. The assignments of the ${ }^{13} \mathrm{C}$ NMR spectra signals of chitosan and the biopolymeric Schiff bases are presented in Table 1.

\section{Atomic absorption spectrometry (AAS)}

Table 2 shows the metal content, $\mathrm{Cu}(\mathrm{II}), \mathrm{Zn}$ (II) and $\mathrm{Ni}(\mathrm{II})$, adsorbed by chitosan and the synthesized Schiff bases determined by atomic absorption spectrometry. The reactions were carried out for $24 \mathrm{~h}$, the time determined for maximum chelating capacity of polymeric compounds. In addition, the $\mathrm{pH}$ of solutions before the complexation reaction was 6.5.

The results showed that chitosan is the most efficient chelating material, in which adsorbed $100 \%$ of $\mathrm{Cu}(\mathrm{II})$ and $\mathrm{Zn}$ (II) and $37 \%$ of $\mathrm{Ni}(\mathrm{II})$. As it was expected, chitosan showed great selectivity for these ions [25].

Due to the chemical modification in the polymer chain, the adsorption capacity of the Schiff bases decreased, which confirms that chelation is related to the $-\mathrm{NH}_{2}$ content as well as to the $-\mathrm{NH}_{2}$ distribution [26]. It can also be considered a steric hindrance of the new groups bonded to chitosan. Comparing the Schiff bases, CTB showed higher chelating capacity, followed by CTDB and CTNB.
Scheme 1 Synthesis of chitosan Schiff bases

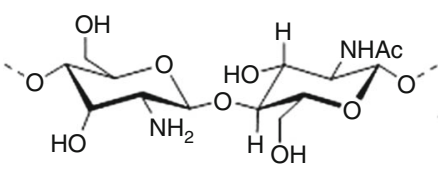

1. Acetic acid 1\% 


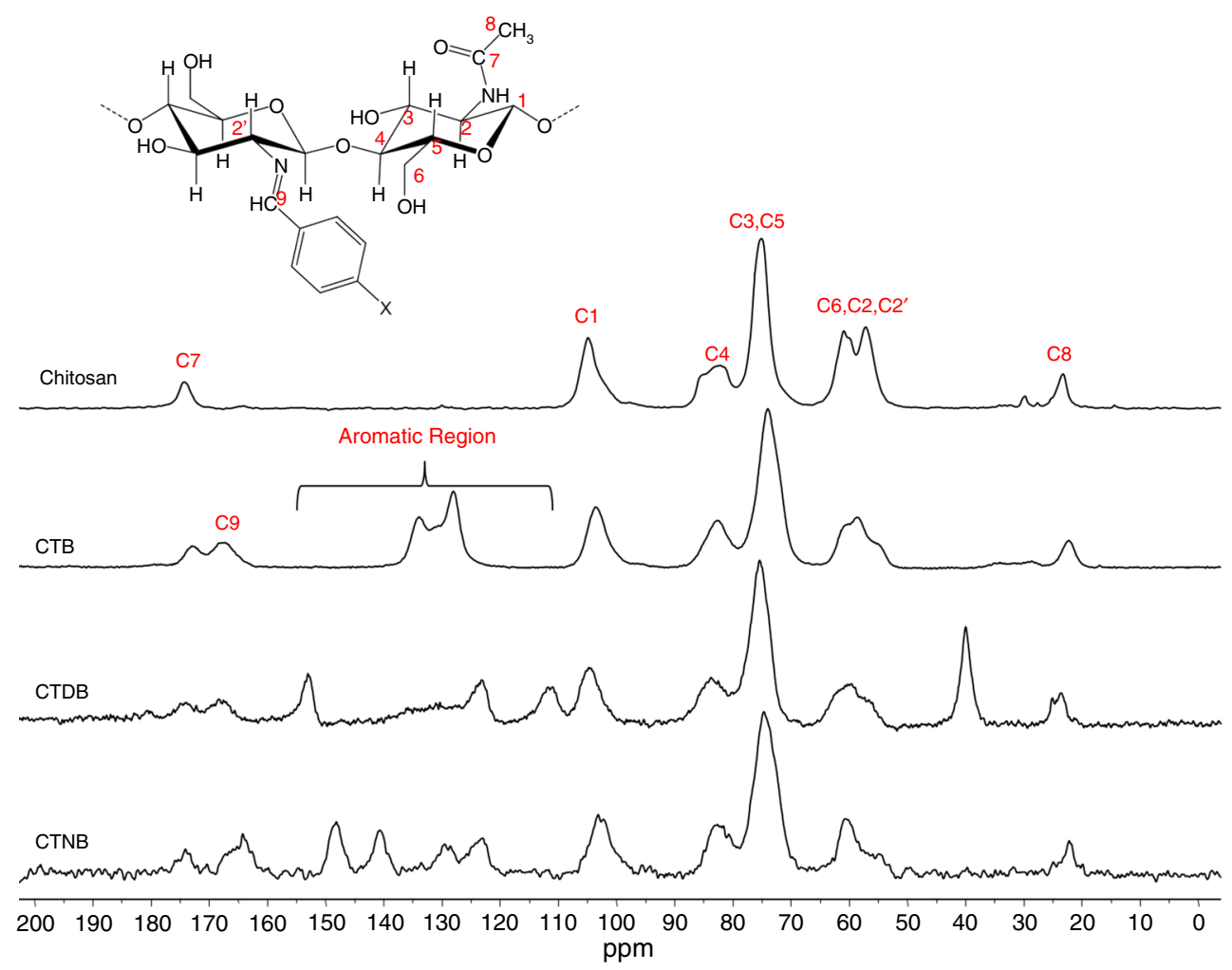

Fig. $1{ }^{13} \mathrm{C}$ CP-MAS NMR spectra of chitosan and Schiff bases

Table 1 Assignments of the ${ }^{13} \mathrm{C}$ NMR spectra signals of chitosan and the biopolymeric Schiff bases

\begin{tabular}{|c|c|c|c|c|c|c|c|c|}
\hline \multirow[t]{2}{*}{ Compound } & \multicolumn{8}{|c|}{ Chemical shift $\delta / p p m$} \\
\hline & $\mathrm{C} 1$ & $\mathrm{C} 6 / \mathrm{C} 2 / \mathrm{C} 2^{\prime}$ & $\mathrm{C} 3, \mathrm{C} 5$ & $\mathrm{C} 4$ & $\mathrm{C} 7$ & $\mathrm{C} 8$ & C9 & Aromatic region \\
\hline \multirow[t]{2}{*}{ Chitosan } & 104.4 & 60.4 & 74.6 & 81.7 & 173.9 & 22.7 & - & - \\
\hline & & 56.6 & & & & & & \\
\hline \multirow[t]{2}{*}{ СТВ } & 104.7 & 60.6 & 70.5 & 82.9 & 171.4 & 23.6 & 164.6 & $128.5-133.6$ \\
\hline & & 58.6 & & & & & & \\
\hline \multirow[t]{2}{*}{ CTDB } & 104.7 & 60.2 & 75.3 & 83.7 & 174.2 & 23.5 & 167.8 & 39.9 \\
\hline & & 57.5 & & & & & & $111.8-152.9$ \\
\hline \multirow[t]{2}{*}{ CTNB } & 103.8 & 61.5 & 75.6 & 83.4 & 174.5 & 23.3 & 164.6 & $124.3-148.6$ \\
\hline & & 55.9 & & & & & & \\
\hline
\end{tabular}

Table 2 Concentration $(\mathrm{mg} / \mathrm{g})$ and percentage of $\mathrm{Cu}^{2+}, \mathrm{Zn}^{2+}$ and $\mathrm{Ni}^{2+}$ ions chelated by chitosan and derivatives at $25^{\circ} \mathrm{C}$ and for $24 \mathrm{~h}$

\begin{tabular}{|c|c|c|c|c|c|c|}
\hline \multirow[t]{2}{*}{ Compound } & \multicolumn{2}{|c|}{$\mathrm{Cu}(\mathrm{II})$} & \multicolumn{2}{|c|}{$\mathrm{Zn}(\mathrm{II})$} & \multicolumn{2}{|l|}{$\mathrm{Ni}(\mathrm{II})$} \\
\hline & $\mathrm{mg} / \mathrm{g}$ & $\%$ & $\mathrm{mg} / \mathrm{g}$ & $\%$ & $\mathrm{mg} / \mathrm{g}$ & $\%$ \\
\hline Chitosan & 64 & 100 & 64 & 100 & 22 & 37 \\
\hline СТВ & 64 & 100 & 31 & 48 & 17 & 30 \\
\hline CTDB & 33 & 53 & 16 & 25 & 3 & 5 \\
\hline CTNB & 9 & 14 & 18 & 27 & 4 & 6 \\
\hline
\end{tabular}

\section{Thermogravimetric analysis (TG/DTG)}

The TG and DTG curves of chitosan are shown in Fig. 2a. Under nitrogen, a two-step degradation is observed, probably due to cross-linking reactions, which occur during thermal decomposition. The first thermal event, at $62{ }^{\circ} \mathrm{C}$ with mass loss of $11 \%$, is assigned to the loss of water adsorbed and/or weakly hydrogen bonded to chitosan [27]. The second thermal event reaches a maximum at $277^{\circ} \mathrm{C}$ 

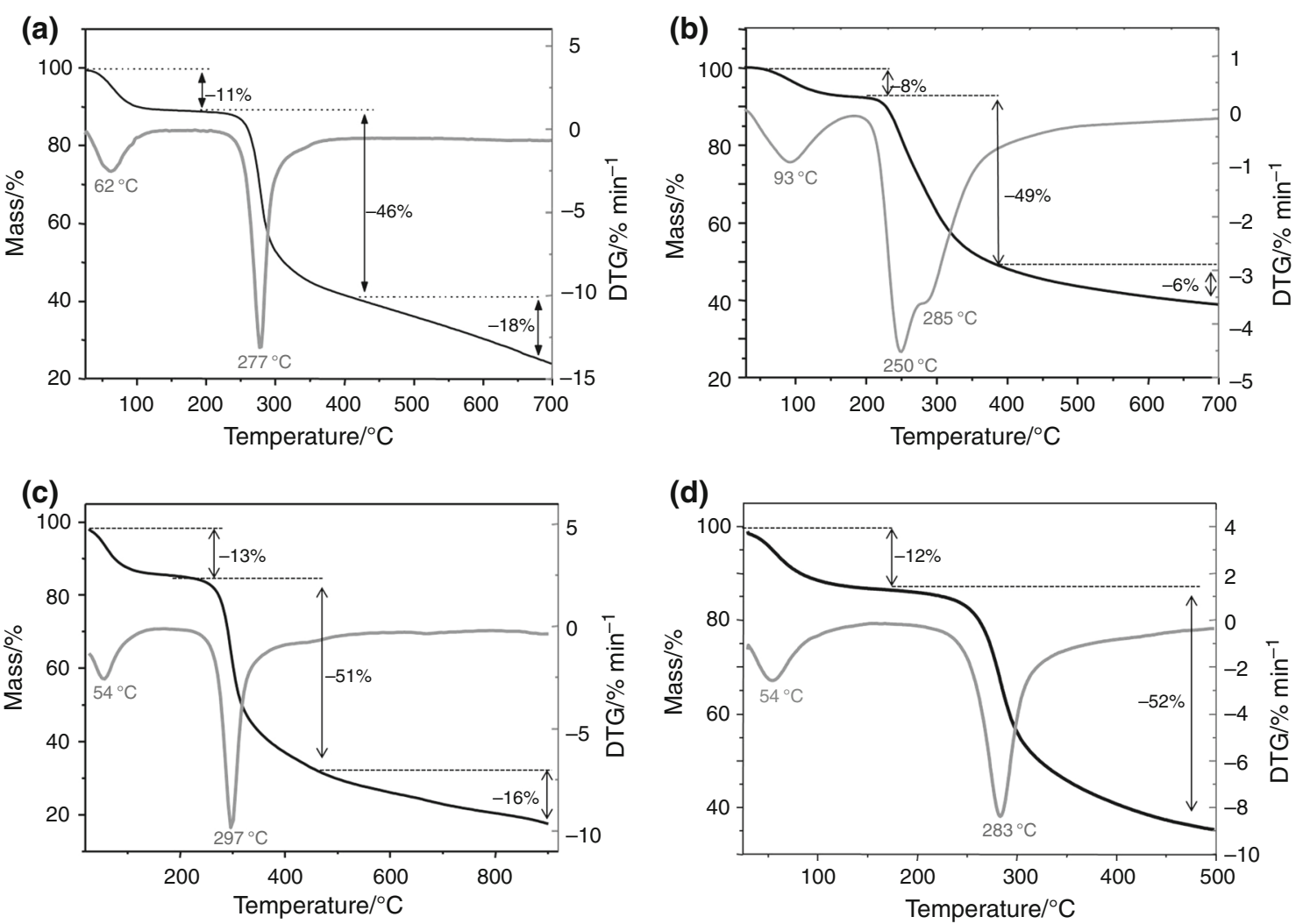

Fig. 2 TG/DTG curves of a chitosan, b chitosan- $\mathrm{Cu}$, $\mathbf{c}$ chitosan- $\mathrm{Zn}$ and $\mathbf{d}$ chitosan-Ni
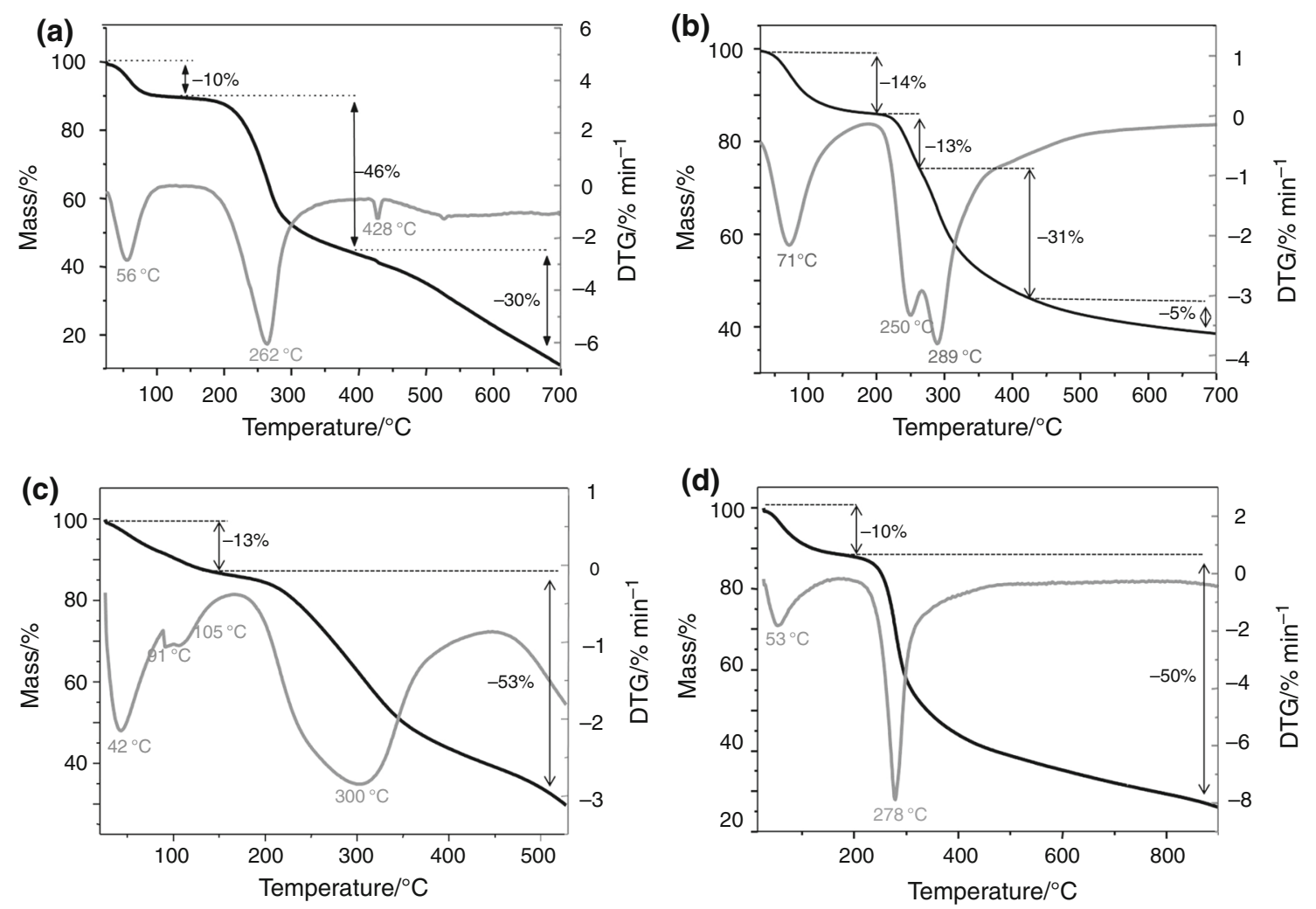

Fig. 3 TG/DTG curves of a CTB, b CTB-Cu, c CTB-Zn and d CTB-Ni 


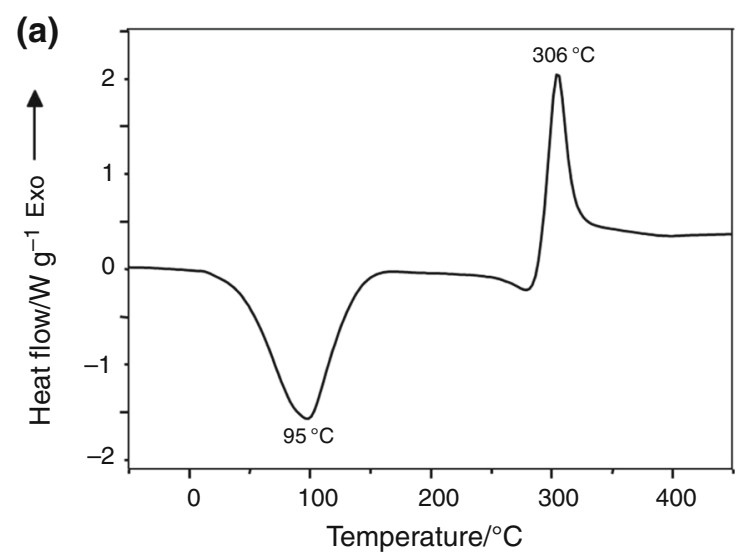

(b)

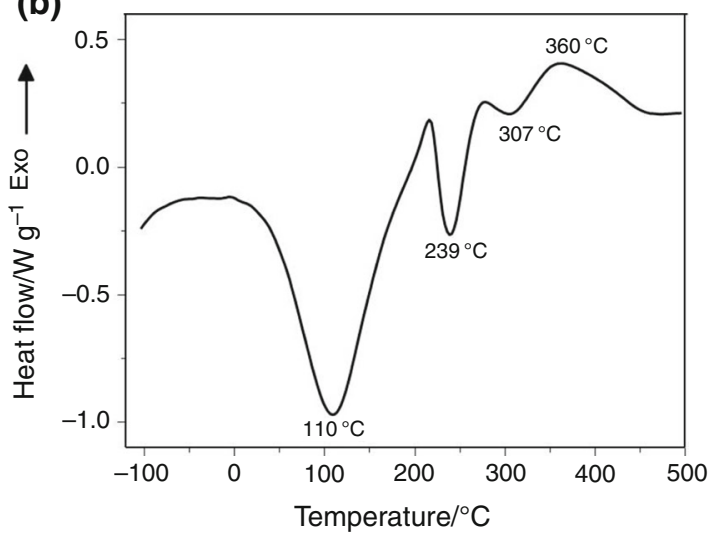

(c)

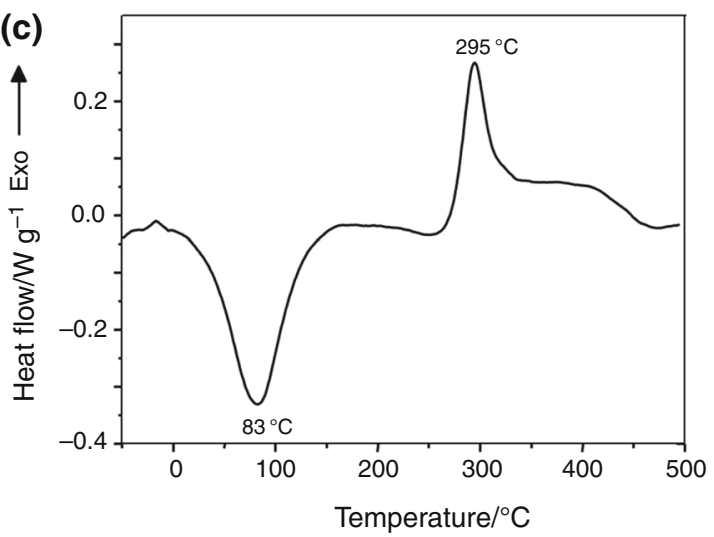

Fig. 4 DSC curve of a Chitosan, b Chitosan-Cu and $\mathbf{c}$ Chitosan-Ni

with a mass loss of $46 \%$. It corresponds to the thermal degradation of the pyranose ring with the rupture of the glycosidic linkages between the glucosamine and $\mathrm{N}$ acetylglucosamine rings on chitosan and release of volatile products [28, 29]. It is also observed a mass loss of $18 \%$ and a residual mass of $25 \%$.

For chitosan- $\mathrm{Cu}$, three thermal events can be observed. In TG/DTG curve, Fig. 2b, there is $8 \%$ mass loss in the first stage between at $93{ }^{\circ} \mathrm{C}$ that is due to the evaporation of the absorbed water. Other two stages are observed at 250 and $285^{\circ} \mathrm{C}$. As the chelation process affects the structural integrity of the polymer, these thermal events may be associated with these structural alterations resulting in the formation of new phases [30]. Nevertheless, TG/DTG curves of chitosan-Zn and chitosan-Ni, Fig. 2c, d respectively, differ from copper complex curves, as only two mass loss stages can be observed. The first thermal events of chitosan zinc and nickel complexes occur at $54{ }^{\circ} \mathrm{C}$ due to the loss of physically adsorbed water molecules. The second thermal event is assigned to the deformation of coordination bond between chitosan and metal ions and also the decomposition of the polymer. After metal complex formation, the thermal stability of chitosan seems to be slightly increased. The residual mass of chitosan- $\mathrm{Cu}$, chitosan- $\mathrm{Zn}$ and chitosan-Ni is 37,20 and $36 \%$.

The TG/DTG curves of CTB, Fig. 3, show three thermal events. The Schiff base lost approximately $10 \%$ of its mass in a first thermal step at $56{ }^{\circ} \mathrm{C}$, which is associated with the release of water. The second stage of thermal degradation appears at $262{ }^{\circ} \mathrm{C}$ with a mass loss of $46 \%$. It is due to the depolymerization of the compound and decomposition of pyranose rings [31]. Another thermal event can be observed at $428{ }^{\circ} \mathrm{C}$ with $30 \%$ of mass loss due to the residual decomposition reactions. The residual mass is $14 \%$. CTB was slightly less stable than chitosan. This fact is related to the reduction in free amino groups due to the chemical modification of the polymer and consequently a lower crystallinity of the Schiff base [22].

Figure $3 b$ shows the TG/DTG curves of CTB-Cu. The first thermal event is observed at $71{ }^{\circ} \mathrm{C}$ with $14 \%$ of mass loss. It is attributed to dehydration of the complex. As observed for chitosan- $\mathrm{Cu}, \mathrm{CTB}-\mathrm{Cu}$ also shows two thermal events in the range of 250 and $289{ }^{\circ} \mathrm{C}$, associated with the formation of new phases due to the presence of metal coordination bonds [30]. For this compound, the residual mass was $37 \%$.

TG/DTG curves of CTB-Zn, Fig. 3c, exhibit two stages for the evaporation of the absorbed water at 42 and $91{ }^{\circ} \mathrm{C}$. At $105{ }^{\circ} \mathrm{C}$, it can be seen the release of strongly hydrogen- 

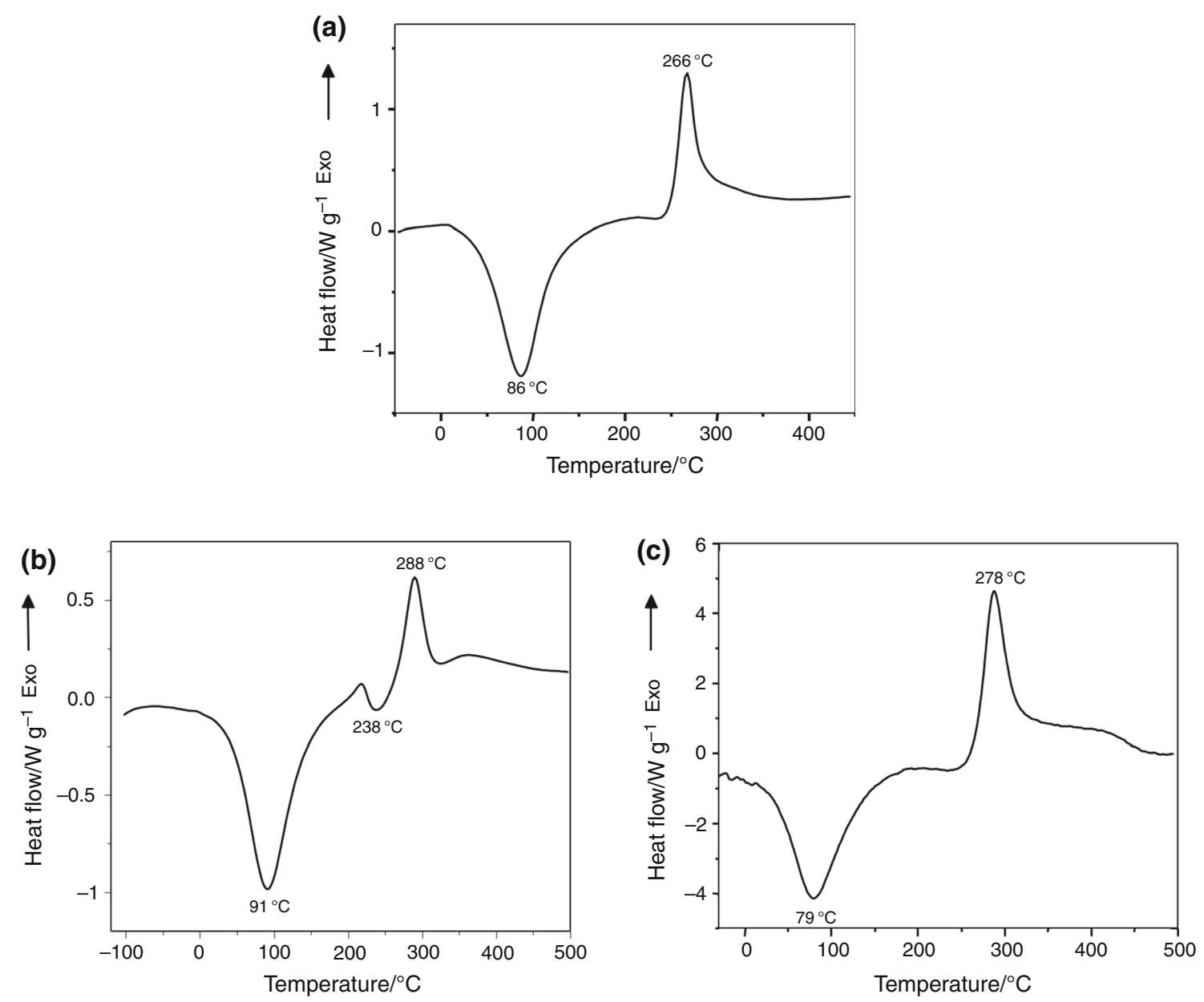

Fig. 5 DSC curve of a CTB, b CTB-Cu and c CTB-Ni

bonded water in the polymeric chain [27]. The depolymerization, derivative decomposition and the deformation of coordination bond occur at $300{ }^{\circ} \mathrm{C}$. The residual mass is $34 \%$.

For CTB-Ni, Fig. 3d, the release of absorbed water is seen at $53{ }^{\circ} \mathrm{C}$ with mass loss of $10 \%$. The second thermal stage occurs at $278{ }^{\circ} \mathrm{C}$, which is due to thermal decomposition of the polymer and coordination bond deformation, with $50 \%$ of mass loss. The residual mass is $40 \%$. The residue amount of CTB complexes is larger than the Schiff base which may be due to the formation of thermally stable metal oxides.

For both chitosan and CTB, the zinc complexes show that thermal degradation occurs at higher temperatures than that of the other complexes which means zinc complex has higher thermal stability than copper and nickel complexes.

\section{Differential Scanning Calorimetry (DSC)}

Figure 4a shows the DSC curve of the polymer chitosan. An endothermic peak, observed at $95{ }^{\circ} \mathrm{C}$, is attributed to the loss of water content. The exothermic peak appears at $306{ }^{\circ} \mathrm{C}$ and corresponds to the decomposition of the polymer chain
[28, 32], due to depolymerization and decomposition of deacetylated and acetylated chitosan units [33]. The DSC curve of chitosan-Cu is represented in Fig. 4b. Differently from chitosan, it shows three endothermic peaks at 110, 239 and $307^{\circ} \mathrm{C}$. The first endothermic peak corresponds to the water removal from the polymer. The other two endothermic transitions may be related to the formation of new phases because of the structural modification of the material due to coordination bonds between the polymer and the metal ion. The exothermic peak, at $360{ }^{\circ} \mathrm{C}$, is attributed to the thermal decomposition of chitosan and the formation of a new and more stable phase [31]. The DSC curve of chitosan-Ni, Fig. 4c, presents a similar profile to chitosan; however, the endothermic and exothermic peaks are slightly shifted to lower temperatures, 83 and $295^{\circ} \mathrm{C}$, respectively, which might be due to the lower amount of $\mathrm{Ni}(\mathrm{II})$ chelated by chitosan.

The thermal behavior of CTB, Fig. 5a, shows an endothermic peak at $86{ }^{\circ} \mathrm{C}$ related to the evaporation of water present in the derivative. The exothermic peak at $266{ }^{\circ} \mathrm{C}$ is associated with the polymer decomposition [32]. Due to the chemical modification, the DSC curve of CTB 

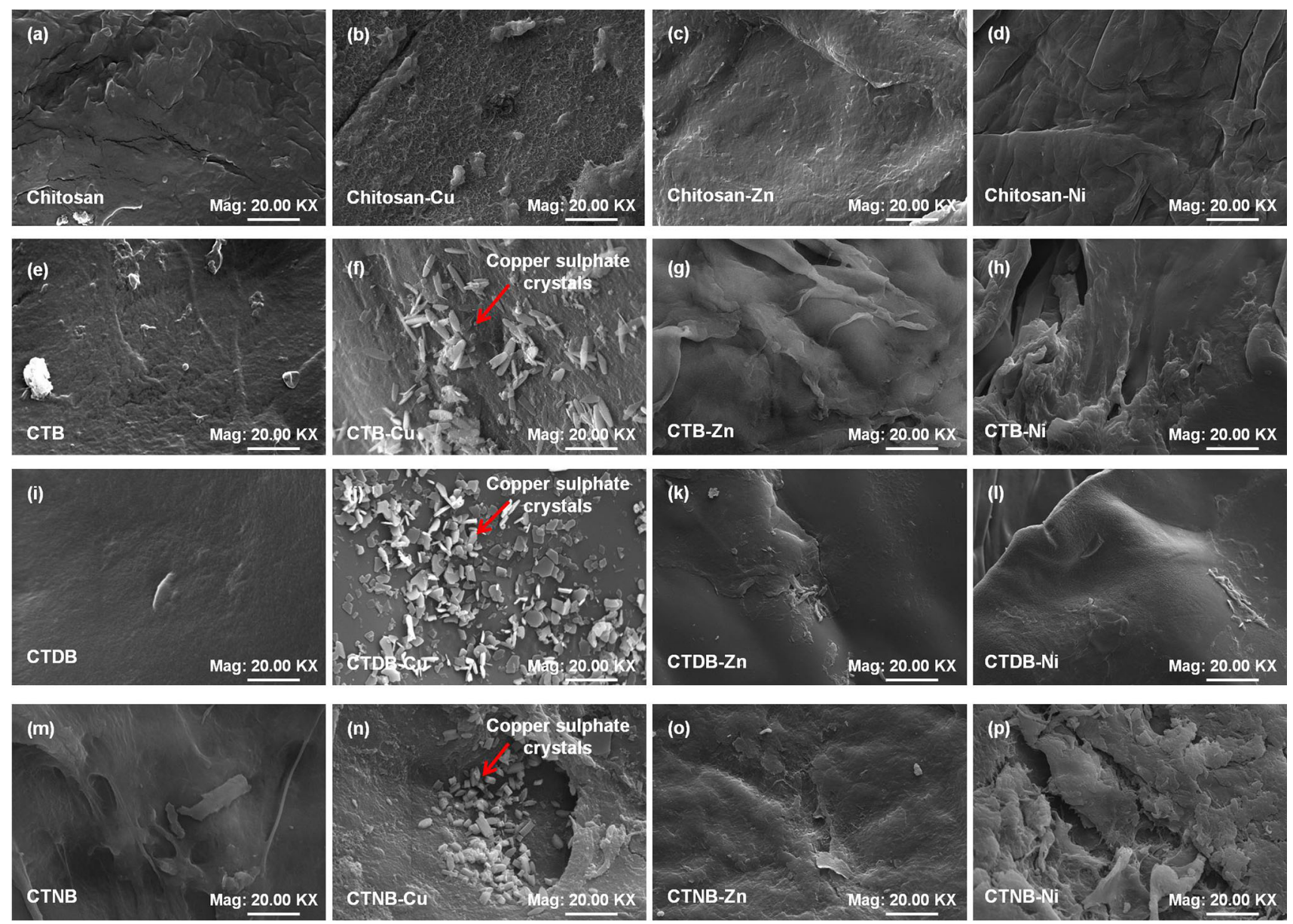

Fig. 6 SEM images of a chitosan-Cu, b chitosan-Zn, $\mathbf{c}$ chitosan-Ni, $\mathbf{d}$ CTB-Cu, e CTB-Zn, f CTB-Ni, $\mathbf{g}$ CTDB-Cu, h CTDB-Zn, i CTDB-Ni, j CTNB-Cu, $\mathbf{k}$ CTNB-Zn and l CTNB-Ni

showed that the derivative is less stable than chitosan as it has shown lower decomposition temperatures, which is in agreement with the results of thermogravimetric analysis. The DSC curve of CTB-Cu, Fig. 5b, exhibits two endothermic peaks at $91{ }^{\circ} \mathrm{C}$ associated with the evaporation of bound water and at $238{ }^{\circ} \mathrm{C}$ related to the formation of new phases due to the coordination bonds between the polymer and the metal ion. The exothermic peak at $288{ }^{\circ} \mathrm{C}$ is attributed to the polymer degradation. The DSC curve of CTB-Ni, represented in Fig. 5c, shows an endothermic peak at $79^{\circ} \mathrm{C}$, related to the evaporation of water. The exothermic peak at $278{ }^{\circ} \mathrm{C}$ is assigned to degradation of the material.

For CTB complexes, the exothermic peaks shifted thermally to higher temperatures when compared to pure CTB. This fact might be associated with the new bonds formed after chelation which enhances thermal stability.

\section{Scanning electron microscopy (SEM)}

The scanning electron micrographs of copper complexes of chitosan (Fig. 6b), CTB (Fig. 6f), CTDB (Fig. 6j) and
CTNB (Fig. 6n), exhibit an irregular surface with the presence of crystals which are attributed to copper sulfate adsorbed on the materials surface [34]. These crystals are not seen in the SEM images of pure materials (Fig. 6a, e, i and $\mathrm{m}$ ). However, the SEM images of zinc complexes (Fig. 6c, g, k and o) only showed smooth and compact morphologies but without the presence of crystals, which suggests that this salt was not adsorbed on the polymers surface. Figure $6 \mathrm{~d}, \mathrm{~h}, 1$ and $\mathrm{p}$ shows the surface morphology of nickel complexes. It can be seen an heterogeneous surface accompanied with pores. In addition, no crystals could be observed on the materials surface.

\section{X-ray powder diffraction (XRD)}

The X-ray diffraction patterns of chitosan, Fig. 7a, showed the characteristic peaks at $2 \theta=10^{\circ}$ and $2 \theta \sim 20^{\circ}$, due to inter- and intra-molecular hydrogen bonds in chitosan [35]. The XRD patterns of its copper complex, Fig. 7a, showed a decrease in the intensity and a broadening of the peaks, which suggest a low crystallinity and an amorphous nature 
(a)

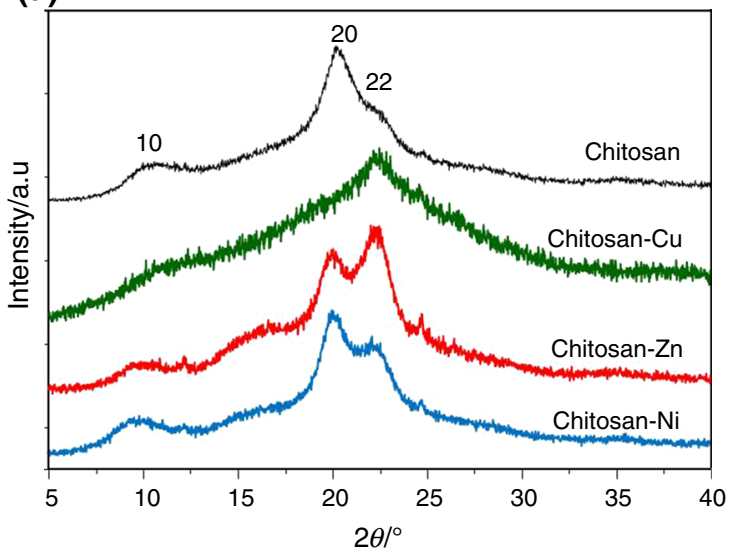

(c)

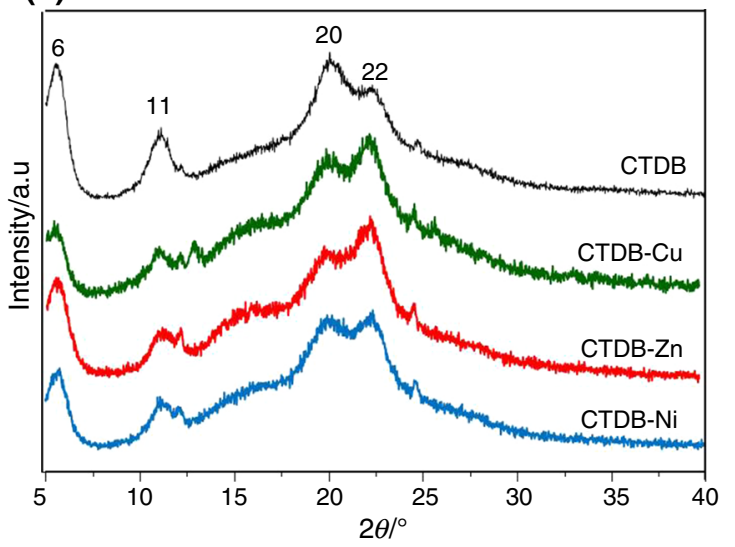

(b)

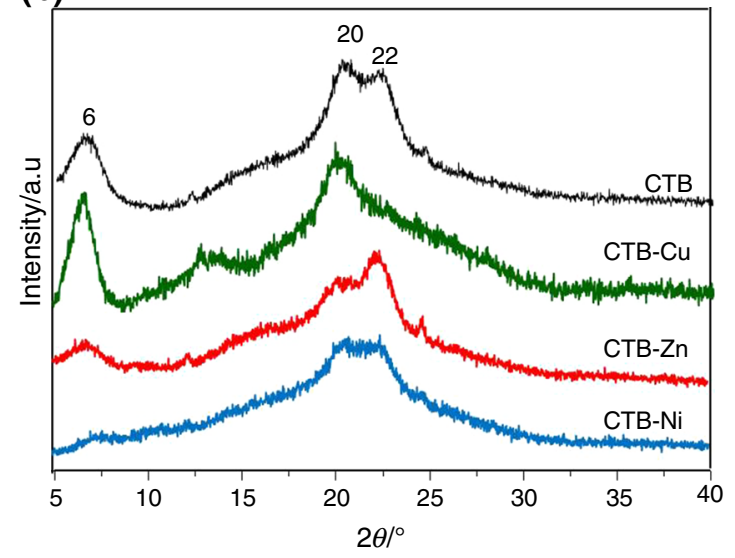

(d)

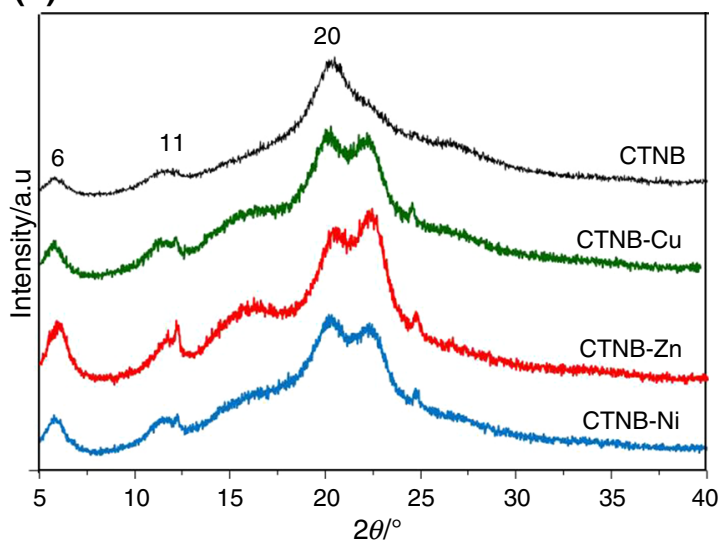

Fig. 7 X-ray diffraction patterns of a chitosan, chitosan-Cu, chitosan-Zn and chitosan-Ni; b CTB, CTB-Cu, CTB-Zn and CTB-Ni; c CTDB, CTDB-Cu, CTDB-Zn and CTDB-Ni; $\mathbf{d}$ CTNB, CTNB-Cu, CTNB-Zn and CTNB-Ni

of the material [14]. On the other hand, X-ray diffraction patterns of zinc and nickel complexes of chitosan, Fig. 7a, were similar to the X-ray patterns of pure chitosan, with poorly defined crystalline diffraction peaks superimposed to haloes characteristic of the amorphous nature of the material. The XRD patterns of Schiff bases, Fig. 7b, c and d, showed a peak at $2 \theta=6^{\circ}$, due to the presence of new groups in the side chain of the polymer [36]. The copper complexes of Schiff bases presented a slight decrease in crystallinity when compared to their respective Schiff base, due to the coordination with the metal ions. In addition, some smaller peaks can also be observed. It is characteristic of pure copper sulfate adsorbed on the materials surface, as confirmed by SEM images.

The X-ray diffraction patterns of $\mathrm{Zn}$ (II) and Ni(II) Schiff bases complexes showed a slight difference when compared to XRD patterns of pure Schiff bases, with more amorphous nature of the polymers after the metal coordination.

The crystallinity of the compounds was calculated using the following Eq. (1):
Crystalline index $(\%)=\left(I_{110}-I_{a m} / I_{110}\right) \cdot 100$

where $I_{110}$ is the maximum intensity at $\sim 20^{\circ}$ and $I_{\mathrm{am}}$ is the intensity of amorphous diffraction at $\sim 10^{\circ}$ [37].

The crystallinity of chitosan derivatives, CTB $57 \%$ and CTDB 55\%, decreased when compared to pure chitosan, 68\%, except for CTNB, $71 \%$. The decrease in the crystallinity of chitosan derivatives may be attributed to the deformation of strong intermolecular hydrogen bonds, because of the substitution in the free amino groups of chitosan [38].

After coordinating with copper ions, chitosan and the Schiff bases have shown a reduction in crystallinity, due to the coordination of the metal with nitrogen atoms and hydroxyl groups of the polymers. Although the CTDB has adsorbed 53\% of copper ions (see Table 2), the crystalline index of CTDB-Cu, 53\%, is only slightly different from pure CTDB, 55\%. This might be due to the fact that for this compound, most of the copper is in the form of salt adsorbed on the material surface, as observed in the SEM images (Fig. 2g). Zn(II) and $\mathrm{Ni}(\mathrm{II})$ complexes also presented lower crystalline index than their Schiff bases. 
Table 3 Crystalline index of chitosan and derivatives and their respective $\mathrm{Cu}(\mathrm{II}), \mathrm{Zn}(\mathrm{II})$ and $\mathrm{Ni}(\mathrm{II})$ complexes

\begin{tabular}{lllll}
\hline Compounds & \multicolumn{4}{l}{ Crystalline index \% } \\
\cline { 2 - 5 } & Pure & $\mathrm{Cu}(\mathrm{II})$ & $\mathrm{Zn}(\mathrm{II})$ & $\mathrm{Ni}(\mathrm{II})$ \\
\hline Chitosan & 68 & 50 & 50 & 64 \\
CTB & 57 & 39 & 53 & 55 \\
CTDB & 55 & 53 & 49 & 52 \\
CTNB & 71 & 62 & 54 & 61 \\
\hline
\end{tabular}

However, the $\mathrm{Zn}(\mathrm{II})$ complexes showed lower crystalline than $\mathrm{Ni}(\mathrm{II})$ complexes. This fact is in agreement with the major concentration of $\mathrm{Zn}^{2+}$ ions chelated by chitosan and their derivatives than $\mathrm{Ni}^{2+}$ ions (see Table 2). The coordination of metal ions to the compounds generates a deformation of strong hydrogen bonds increasing the disorder of the systems and, consequently, decreasing their crystallinity.

Table 3 shows the calculated crystalline index values for all compounds.

\section{Conclusions}

Three chitosan Schiff bases with aromatic substituent groups have been synthesized and characterized by ${ }^{13} \mathrm{C}$ NMR in solid state. The AAS results showed that chitosan presents higher chelating capacity than the derivatives in the order $\mathrm{Cu}>\mathrm{Zn}>\mathrm{Ni}$. The morphology studies exhibited copper sulfate adsorbed on the polymers surface, which indicates that part of the metal content determined by AAS is in the salt adsorbed. The crystals were not observed for the other metal complexes. X-ray diffraction patterns showed that the presence of new groups on chitosan chain as well as the formation of complexes resulted in the decrease in crystallinity. This decrease can be attributed to the deformation of strong hydrogen bonds when the metal ions are coordinated to the compounds. TG/DTG measurements showed a decrease in the decomposition temperature of CTB when compared to nonmodified chitosan. Furthermore, the presence of coordination bonds between the metal ions and the materials increased their thermal stability. Differently from zinc and nickel complexes, the curves of copper complexes presented more thermal events related to the formation of new phases and the copper salt adsorbed on the materials surface. DSC curves of copper complexes showed more endothermic transitions than the other complexes. In addition, exothermic peaks of CTB complexes shifted thermally to higher temperatures when compared to pure CTB.
Acknowledgements The authors gratefully thank Fundação de Apoio a Pesquisa do Estado de São Paulo (FAPESP), 2012/13901-3, 2013/26576-6 fellowships and research fund 2013/24487-6. The authors thank Élton J. Souza and Glenda Gonçalves de Souza for scanning electron microscopy analyses.

\section{References}

1. Varma AJ, Deshpande SV, Kennedy JF. Metal complexation by chitosan and its derivative: a review. Carbohydr Polym. 2004; 55:77-93.

2. Gomes P, Gomes CAR, Batista MKS, Pinto LF, Silva PAP. Novel highly-soluble peptide-chitosan polymers: chemical synthesis and spectral characterization. Carbohydr Polym. 2008;71:54-65.

3. Aiping Z, Jianhong L, Wenhui Y. Effective loading and controlled release of camptothecin by O-carboxymethylchitosan aggregates. Carbohydr Polym. 2006;63:89-96.

4. Soliman EA, El-Kousy SM, Abd-Elbary HM, Abou-zeid AR. Low molecular weight chitosan-based Schiff bases: synthesis, characterization and antimicrobial activity. Am J Food Technol. 2013;8:17-30.

5. Sajomsang W, Tantayanon S, Tangpasuthadol V, Thatte M, Daly WH. Synthesis and characterization of N-aryl chitosan derivatives. Int J Biol Macromolec. 2008;43:79-87.

6. Tirkistani FAA. Thermal analysis of some chitosan Schiff base. Polym Degrad Stabil. 1998;60:67-70.

7. Yin X, Chen J, Yuan W, Lin Q, Ji L, Liu F. Preparation and antibacterial activity of Schiff bases from O-carboxymethyl chitosan and para-substituted benzaldehydes. Polym Bull. 2012;68:1215-26.

8. Lal S, Arora S, Sharma C. Synthesis, thermal and antimicrobial studies of some Schiff bases of chitosan. J Therm Anal Calorim. 2016;124:909-16.

9. Jiao T, Zhao H, Zhou J, Zhang Q, Luo X, Hu J, Peng Q, Yan X. Self-assembly reduced graphene oxide nanosheet hydrogel fabrication by anchorage of chitosan/silver and its potential efficient application toward dye degradation for wastewater treatments. ACS Sustain Chem Eng. 2015;12:3130-9.

10. Zhao H, Jiao T, Zhang L, Zhou J, Zhang Q, Peng Q, Yan X. Preparation and adsorption capacity evaluation of graphene oxide-chitosan composite hydrogels. Sci China Mater. 2015;58: $811-8$.

11. Mohamed RR, Fekry AM. Antimicrobial and anticorrosive activity of adsorbents based on chitosan Schiff's base. Int J Electrochem Sci. 2011;6:2488-508.

12. Gavalyan VB. Synthesis and characterization of new chitosanbased Schiff base compounds. Carbohydr Polym. 2016;145: $37-47$.

13. Tong JH, Li Z, Xia CG. Highly efficient catalysts of chitosanSchiff base Co(II) and Pd(II) complexes for aerobic oxidation of cyclohexane in the absence of reductants and solvents. J Mol Catal A: Chem. 2005;231:197-203.

14. Leonhardt SES, Stolle A, Ondruschka B, Cravotto G, De Leo C, Jandt KD, Keller TF. Chitosan as a support for heterogeneous Pd catalysts in liquid phase catalysis. Appl Catal A Gen. 2010; 379:30-7.

15. Parrey IR, Bhat AR, Hashmi AA. Catalytic activity of benzyl alcohol using modified chitosan schiff base $\mathrm{Cu}(\mathrm{II})$ metal complex. Int J Sci Eng Res. 2014;10:829-33.

16. Vadivel T, Dhamodaran M, Singaram K. Antibacterial activities of palladium (II) complexes derived from chitosan biopolymer Schiff base. J Bacteriol Mycol. 2015;2:1018-22. 
17. Anan NA, Hassan SM, Saad EM, Butler IS, Mostafa IS. Preparation, characterization and $\mathrm{pH}$-metric measurements of 4-hydroxysalicylidenechitosan Schiff-base complexes of $\mathrm{Fe}(\mathrm{III})$, $\mathrm{Co}(\mathrm{II}), \mathrm{Ni}(\mathrm{II}), \mathrm{Cu}(\mathrm{II}), \mathrm{Zn}(\mathrm{II}), \mathrm{Ru}(\mathrm{III}), \mathrm{Rh}(\mathrm{III}), \mathrm{Pd}(\mathrm{II})$ and $\mathrm{Au}(\mathrm{III})$. Carbohydr Res. 2011;346:775-93.

18. Krishnapriya KR, Kandaswamy M. A new chitosan biopolymer derivative as metal-complexing agent: synthesis, characterization, and metal(II) ion adsorption studies. Carbohydr Polym. 2010; 345:2013-22.

19. Jiao T, Zhou J, Zhou J, Gao L, Xing Y, Li X. Synthesis and characterization of chitosan-based Schiff Base compounds with aromatic substituent groups. Iran Polym J. 2011;20:123-36.

20. Thatte CS, Rathnam MV, Pise AC. Chitosan-based Schiff basemetal complexes ( $\mathrm{Mn}, \mathrm{Cu}, \mathrm{Co})$ as heterogeneous, new catalysts for the $\beta$-isophorone oxidation. J Chem Sci. 2014;126:727-37.

21. Antony R, David ST, Saravanan K, Karuppasamy K, Balakumar S. Synthesis, spectrochemical characterisation and catalytic activity of transition metal complexes derived from Schiff base modified chitosan. Spectrochim Acta Mol Biomol Spectrosc. 2013;103:423-30.

22. Salama HE, Saad GR, Sabaa MW. Synthesis, characterization and biological activity of Schiff bases based on chitosan and arylpyrazole moiety. Int J Biol Macromol. 2015;79:996-1003.

23. Mohammad RK. The use of various types of NMR and IR spectroscopy for structural characterization of chitin and chitosan. Chitin, chitosan, oligosaccharides and their derivatives, biological activities and applications, EUA, chapter 12; 2011.

24. Young DH, Kauss H. Release of calcium from suspension-cultured Glycine max cells by chitosan, other polycations, and polyamines in relation to effects on membrane permeability. Plant Physiol. 1983;73:698-702.

25. Rinaudo M. Chitin and chitosan: properties and applications. Prog Polym Sci. 2006;31:603-32.

26. Kurita K, Sannan T, Iwakura Y. Studies on chitin. VI. Binding of metal cations. J Appl Polym Sci. 1979;23:511-5.
27. Zawadzki J, Kaczmarek H. Thermal treatment of chitosan in various conditions. Carbohydr Polym. 2010;80:394-400.

28. Pereira FS, da Agostini DLS, Job AE, González ERP. Thermal studies of chitin-chitosan derivatives. J Therm Anal Calorim. 2013;114:321-7.

29. Tang WJ, Wang CX, Donghua C. Kinetic studies on the pyrolysis of chitin and chitosan. Polym Degrad Stab. 2005;87:389-94.

30. Sreenivasan K. Thermal stability studies of some chitosan metal ion complexes using differential scanning calorimetry. Polym Degrad Stab. 1996;52:85-7.

31. Sashikala S, Shafi SS. Synthesis, Characterization and Antimicrobial activity of chitosan 4-chlorobenzaldehyde Schiff base. Res J Chem Sci. 2015;5:27-33.

32. Koll P, Borchers G, Metzger JO. Thermal degradation of chitin and cellulose. J Anal Appl Pyrolysis. 1991;19:119-29.

33. Mathew S, Brahmakumar M, Abraham TE. Microstructural imaging and characterization of the mechanical, chemical, thermal, and swelling properties of starch-chitosan blend films. Biopolymers. 2006;82:176-87.

34. Pereira FS, Souza GG, Moraes PGP, Barroso RP, Lanfredi S, Gomes HM, Costa-Filho AJ, González ERP. Study of chitosans interaction with $\mathrm{Cu}$ (II) from the corresponding sulfate and chloride salts. Cellulose. 2015;22:2391-407.

35. Haas LK, Franz JK. Application of metal coordination chemistry to explore and manipulate cell biology. Chem Rev. 2009;109: 4921-60.

36. Li-xia W, Zi-wei W, Guo-song W, Xiao-dong L, Jian-guo R. Catalytic performance of chitosan-Schiff base supported $\mathrm{Pd} / \mathrm{Co}$ bimetallic catalyst for acrylamide with phenyl halide. Polym Adv Technol. 2010;21:244-9.

37. Focher B, Beltrame PL, Naggi A, Torri G. Alkaline N-deacetylation of chitin enhanced by flash treatments. reaction kinetics and structure modification. Carbohydr Polym. 1990;12:405-18.

38. Jeon C, Höll WH. Chemical modification of chitosan and equilibrium study for mercury ion removal. Water Res. 2003;37:4770-80. 